\title{
Electrochemical Oxidation Effect of Nicotine in Cigarette Tobacco on a Blood Medium Mediated by GCE Using Cyclic Voltammetry
}

\author{
Muhammed M. Radhi, ${ }^{a, *}$ Mohammed A. Ali Alasady ${ }^{b}$ and Majid S. Jabir ${ }^{c}$ \\ ${ }^{a}$ Radiological Techniques Department, Health and Medical Technology College-Baghdad, \\ Middle Technology University, Baghdad, Iraq \\ ${ }^{b}$ Plant Protection Center, Baghdad, Iraq \\ ${ }^{c}$ Applied Science Department, University of Technology-Baghdad, Iraq
}

Received March 13, 2017; accepted April 16, 2018

\begin{abstract}
The electrochemical behaviour of nicotine extracted from commercial cigarette tobacco were studied in a blood media, at a glassy carbon electrode (GCE), using cyclic voltammetry technique. The nicotine compound oxidized the blood component in neutral media, at $\mathrm{pH}$ 7.4. The response was evaluated with respect to different $\mathrm{pH}$ values, scan rates, concentrations and temperatures. From the voltammogram of nicotine in a blood medium, it was found that the oxidation current peak of nicotine was $+999 \mathrm{mV}$ in acidic and alkaline media, which enhanced about twice in an acidic medium and disappeared in an alkaline medium. In its turn, at highly acidic media, three reduction current peaks appeared in the nicotine voltammogram in blood media.

The electrochemical behavior of nicotine was investigated using cyclic voltammetry technique; the method was successfully applied for the determination of the nicotine compound which had a reversible redox couple in a blood medium from the peak potential separation of $100 \mathrm{mV}$. Also, it was found that the average value of the diffusion coefficient at the cathodic electrode was $4.075 \times 10^{11} \mathrm{~cm}^{-2} \mathrm{~s}^{-1}$, and $22.625 \times 10^{11}$ $\mathrm{cm}^{-2} \mathrm{~s}^{-1}$ at the anodic electrode.
\end{abstract}

Keywords: nicotine, cyclic voltammetry, blood and glassy carbon electrode.

\section{Introduction}

Cigarettes'nicotine is influential in relation to smokers' health, by the release of free radicals which results in the oxidation of blood components. The electrochemical method by cyclic voltammetry analysis can be used to determine nicotine effects on blood components.

Many studies using the electrochemical method by cyclic voltammetry have discussed the effect of different chemical compounds as pollutants which contact with human life in substances such as heavy metals [1-7].

\footnotetext{
* Corresponding author. E-mail address: mmradhi@yahoo.com
} 
Nicotine compound structure 3-(1-methyl-2-pyrrolidinyl), pyridine, is the main alkaloid in tobacco leaves [8]. It has been reported that over 4000 compounds exist in tobacco smoke, with at least 50 known to be carcinogenic [9-10], and more than 20 different alkaloids are found in tobacco and processed tobacco products [11].

Blood nicotine and carboxyhemoglobin concentrations were studied on different smokers. The results of some studies have showed the nicotine yield of the cigarettes, which accounted for the variation in blood nicotine concentrations. The findings of epidemiological studies show a lower risk with filter-tipped cigarettes, which may be attributable to other factors such as biases in the samples and changes in the quality and carcinogenicity of the tobacco tar, rather than to the reduced tar intake [12].

Nicotine is primarily metabolized by CYP2A6, UDP-glucuronosyltransferase liver enzymes and Flavin-containing monooxygenase. The most widely used biomarker of nicotine intake is cotinine, which may be measured in blood, urine, saliva, hair, or nails. In addition to the genetic factors, nicotine metabolism is influenced by diet and meals, age, sex, use of estrogen-containing hormone preparations, pregnancy and kidney disease, other medications, and smoking itself [13].

There are frequent warnings of adverse cardiovascular effects of nicotine, claiming that it may cause atherosclerosis, leading to an enhanced risk of severe diseases, such as myocardial infarction or stroke. The harm caused by tobacco smoke is well established, but the contribution of nicotine to cardiovascular disease is less clear [14].

Nicotine may contribute to cardiovascular disease; however, there are many potential cardiovascular toxins in cigarette smoke other than nicotine. Cigarette smoking increases blood coagulability, a major risk factor for acute cardiovascular events, whereas transdermal nicotine does not appear to do so [15].

In this work, the study of the effects of tobacco's nicotine in a blood medium has been done using electrochemistry method by cyclic voltammetry.

\section{Experimental}

\section{Extraction of nicotine and chemical reagents}

Nicotine was extracted from commercial cigarette tobacco in an aqueous solution; the nicotine stock solution was used in the experimental study after purification. All experiments were carried out at room temperature $\left(25^{\circ} \mathrm{C}\right)$.

Other chemicals and solvents were of annalar grade, and were used as-received from the manufacturer. Double distilled water was used for the preparation of the aqueous solutions. All solutions were de-aerated with oxygen free nitrogen gas for $15 \mathrm{~min}$ prior to making the measurements.

\section{Instrumentation}

EZstat series (potentiostat/glvanostat) NuVant Systems Inc. pioneering electrochemical technologies, USA, electrochemical workstations of Bioanalytical system with a potentiostat driven by electroanalytical measuring 
software were connected to a personal computer to perform cyclic voltammogram. $\mathrm{Ag} / \mathrm{AgCl}(3 \mathrm{M} \mathrm{NaCl})$ and platinum wire $(1 \mathrm{~mm}$ diameter) were used as reference and counter electrodes, respectively.

\section{Results and discussion}

\section{Calibration curve}

Cyclic voltammogram of nicotine in blood media was selected for the analytical determination of its redox current peaks, due to its high sensitivity through GCE in cyclic voltammetry, at different concentrations The linear relationship dependence of the peak currents on the concentration of the analytic compound was obtained for different concentrations of nicotine, in the range from 1 to 200 $\mathrm{mM}$. The peak current at $+0.83 \mathrm{~V}$ linearly increased with nicotine concentration with a linear regression equation: $\mathrm{i}_{\mathrm{pa}}(\mu \mathrm{A})=0.3959+0.05 \mathrm{C}(\mu \mathrm{M})\left(\mathrm{R}^{2}=0.998\right)$. The calculated $(3, \mathrm{n}=6)$ limit of detection for nicotine was $0.7 \mu \mathrm{M}$.

\section{Effect of different $\mathrm{pH}$ values of the blood medium}

The study of the nicotine compound in different $\mathrm{pH}$ values of the blood medium was determined at neutral $\mathrm{pH}=7$, as shown in Fig. 1, which illustrated an oxidation current peak at $750 \mathrm{mV}$. These results mean that nicotine worked as an oxidative reagent on a neutral blood medium.

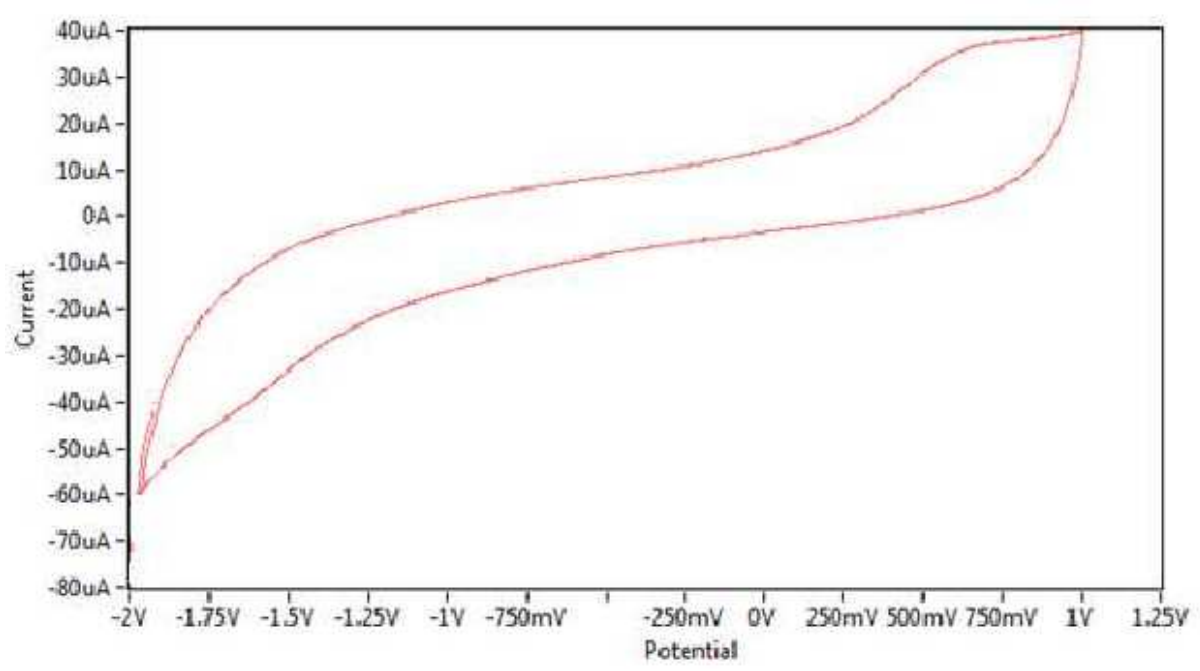

Figure 1. Cyclic voltammogram of nicotine in a blood medium at $\mathrm{pH}=7$, using GCE and $\mathrm{Ag} / \mathrm{AgCl}$ as reference electrodes, with a scan rate of $100 \mathrm{mV} \mathrm{s}^{-1}$.

The cyclic voltammogram of nicotine in an acidic blood medium was shown in Fig. 2. One oxidation current peak was found at $600 \mathrm{mV}$, and two reduction peaks at $-500 \mathrm{mV},-1.25 \mathrm{~V}$ in a blood medium of $\mathrm{pH}=4$. So, the acidic blood medium acted on the nicotine compound as anti-oxidative reagent at this $\mathrm{pH}$, as shown in the equation at Scheme 1 [16-17]: 
<smiles>CN1CCCC1c1cccnc1</smiles>

Scheme 1. Converted nicotine compound at acidic $\mathrm{pH}$ values.

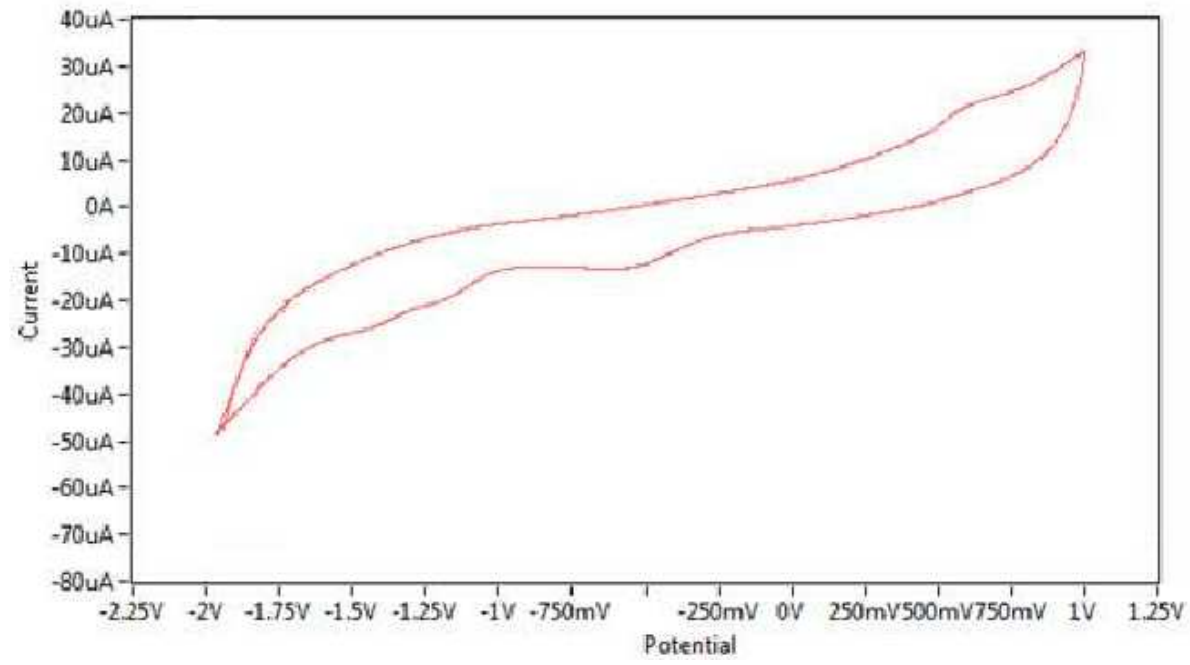

Figure 2. Cyclic voltammogram of nicotine in a blood medium at $\mathrm{pH}=4$, using GCE and $\mathrm{Ag} / \mathrm{AgCl}$ as reference electrodes, with a scan rate of $100 \mathrm{mV} \mathrm{s}^{-1}$.

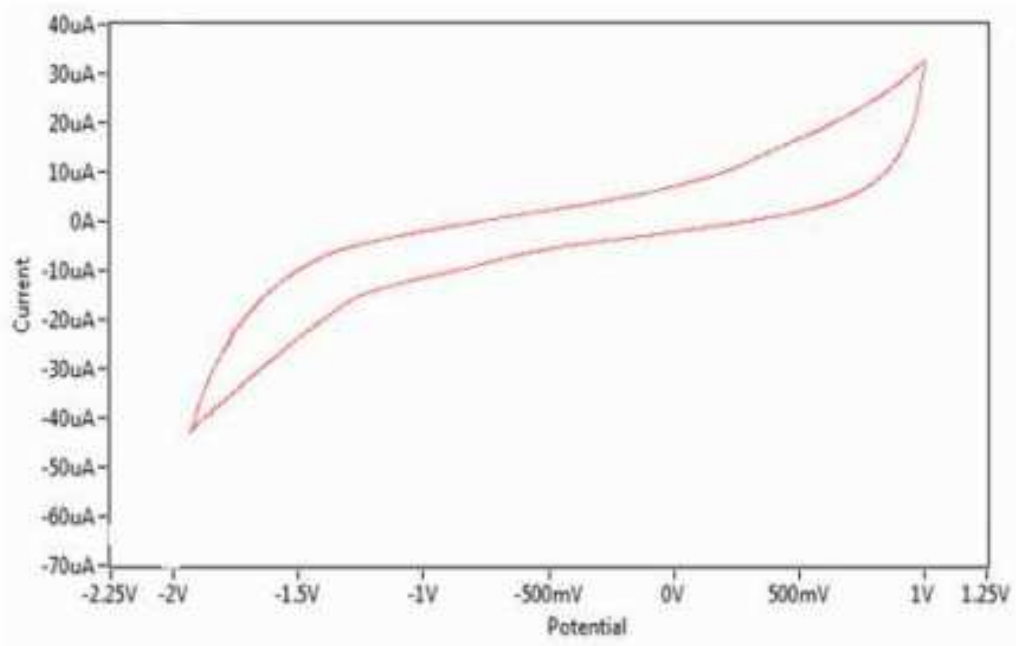

Figure 3. Cyclic voltammogram of nicotine in a blood medium at $\mathrm{pH}=8$, using GCE and $\mathrm{Ag} / \mathrm{AgCl}$ as reference electrodes, with a scan rate of $100 \mathrm{mV} \mathrm{s}^{-1}$.

The results were different when it was used an alkaline blood medium, at $\mathrm{pH}=8$, with the nicotine compound.

Fig. 3 shows the cyclic voltammogram of nicotine in an alkaline blood medium without any current peak. There are three cases of the nicotine compound at different $\mathrm{pH}$ values of the blood medium which explain the oxidation stress of 
nicotine at neutral and acidic blood media. Fig. 4 shows the different $\mathrm{pH}$ values in the medium for the nicotine compound.

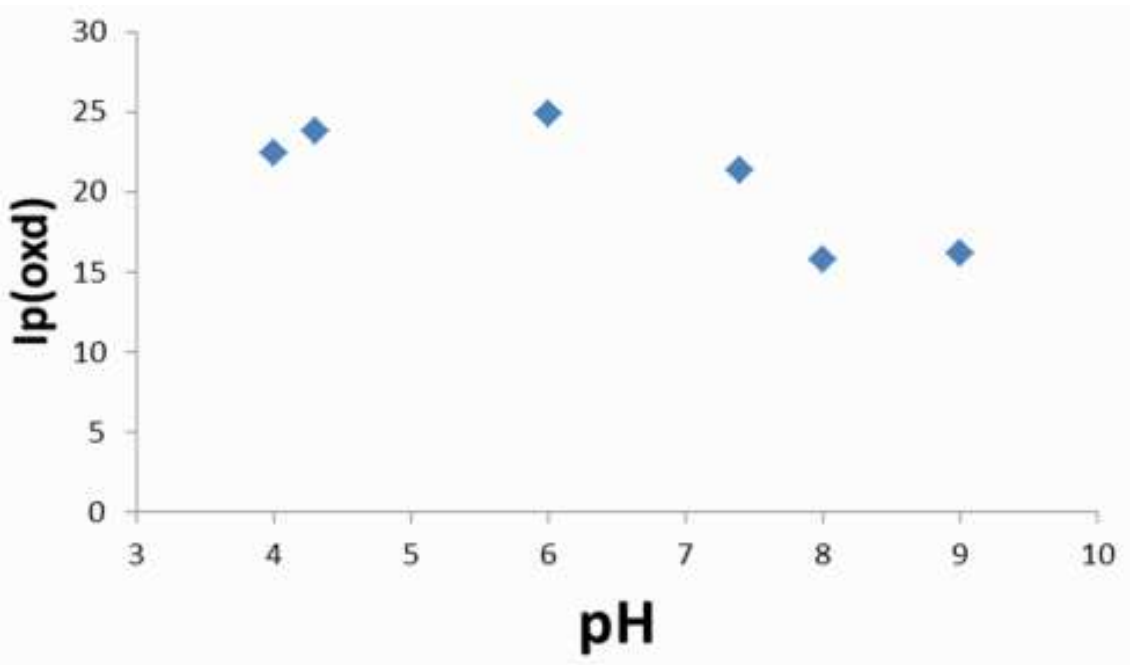

Figure 4. Plot of the oxidation current peak of nicotine against different $\mathrm{pH}$ values of the blood medium, at $\mathrm{GCE}$ and $\mathrm{Ag} / \mathrm{AgCl}$ as reference electrodes, with a scan rate of $100 \mathrm{mV} \mathrm{s}^{-1}$.

\section{Effect of different temperatures in a blood medium}

It was studied the nicotine compound in a blood medium at different temperatures $\left(30-60{ }^{\circ} \mathrm{C}\right)$. The oxidation - reduction current peaks of nicotine were gradually enhanced against increasing temperatures, as shown in Fig. 5.

Fig. 6 illustrates the plot of $\log \left(\mathrm{I}_{\mathrm{pa}}\right)$ of nicotine in a blood medium versus the reciprocal of temperature on GCE, with a good linear relationship of the equation $\mathrm{Y}=-1.0333 \mathrm{X}+4547$ and $\mathrm{R}^{2}=0.8094$. According to Arrhenius equations 1 and 2 [18-19], the activation energy for the oxidation - reduction process of the converted nicotine compound in a blood medium was $19.75 \mathrm{KJ} / \mathrm{mol}$. $\mathrm{K}$ is a result from the slope of the equation in Fig. 6.

$$
\begin{aligned}
& \sigma=\sigma^{\circ} e^{-\mathrm{Ea} / \mathrm{RT}} \\
& \mathrm{D}=\mathrm{D}^{\circ} \mathrm{e}^{-\mathrm{Ea} / \mathrm{RT}}
\end{aligned}
$$

where $\sigma / \mathrm{D}$ is the conductivity/ diffusibility; $\sigma^{\circ} / \mathrm{D}^{\circ}$ is the standard conductivity/ initial diffusibility; $\mathrm{E}_{\mathrm{a}}$ is the activation energy; $\mathrm{R}$ is the universal gas constant; and $\mathrm{T}$ is the temperature.

\section{Effect at different scan rates}

A linear relationship was dependent on the nicotine compound in a blood medium at the oxidation current peak against different increasing scan rates (SR), which are described by equations $\mathrm{Y}=0.6461 \mathrm{X}+1.9714$ and $\mathrm{R}^{2}=0.91$, as shown in Fig. 7. 


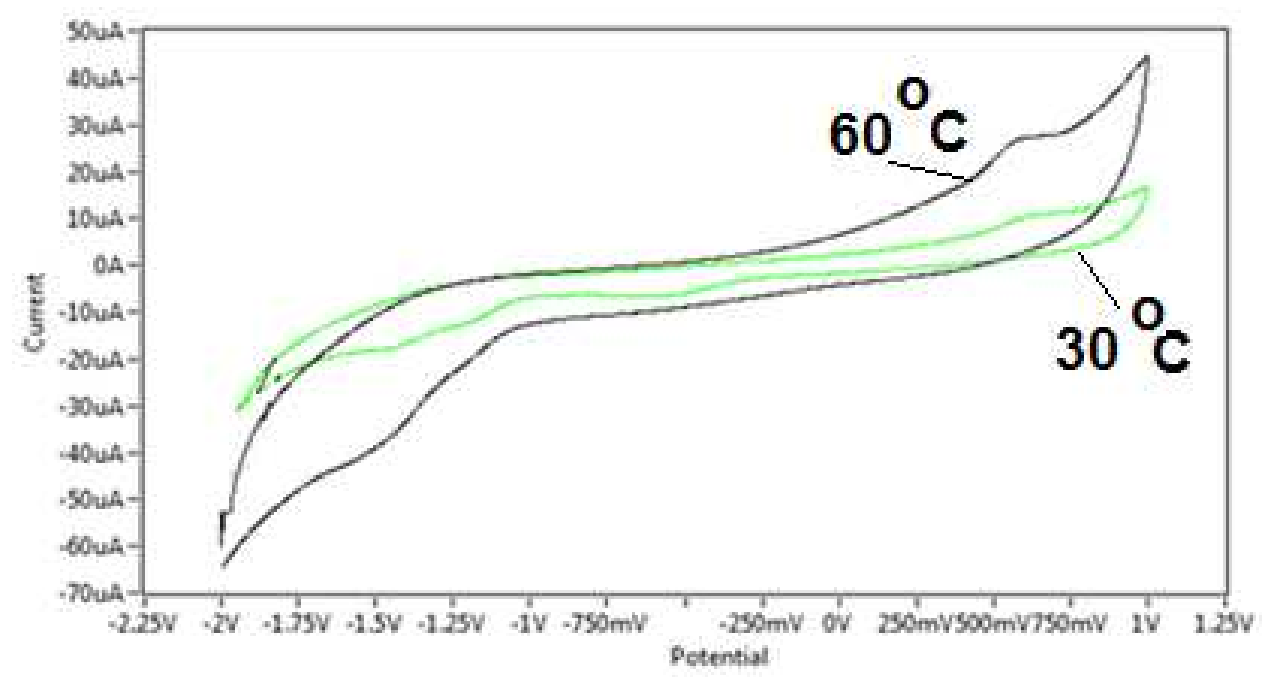

Figure 5. Cyclic voltammogram of nicotine in a blood medium at different temperatures, using $\mathrm{GCE}$ and $\mathrm{Ag} / \mathrm{AgCl}$ as reference electrodes.

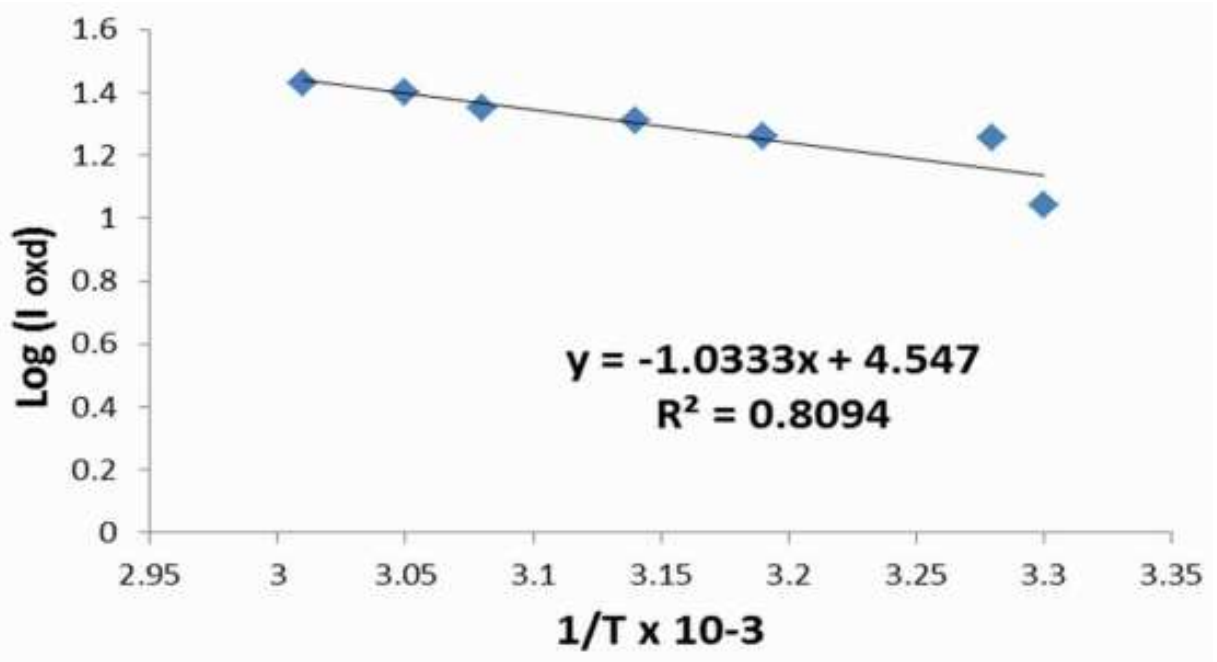

Figure 6. Plot of $\log \left(\mathrm{I}_{\mathrm{pa}}\right)$ oxidative current peak against different inverse temperatures $(1 / \mathrm{T})$ of nicotine in a blood medium.

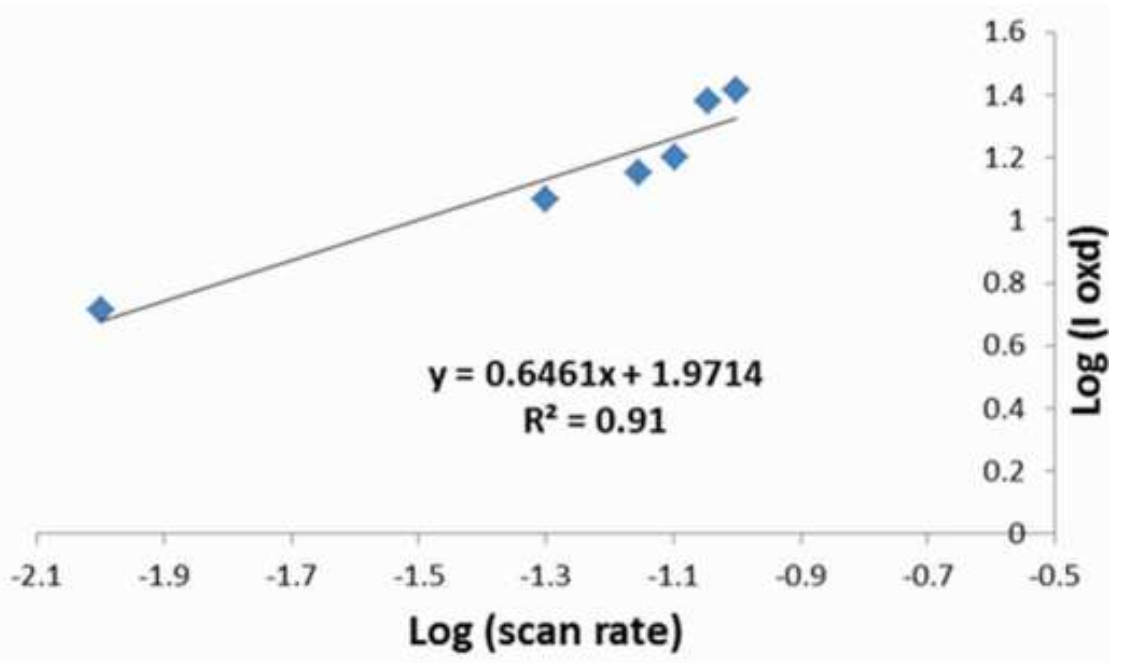

Figure 7. Plot of $\log \left(\mathrm{I}_{\mathrm{pa}}\right)$ against the $\log (\mathrm{SR})$ of the nicotine compound in a blood medium at GCE, at different scan rates. 


\section{Peak separation current ratio and diffusion coefficient of nicotine}

It was found from Table 1 that the average value of the peak potential separation of redox current peaks of nicotine in a blood medium is $100 \mathrm{mV}$; this value indicates that the redox reaction of nicotine compound has a reversible redox couple in the blood medium. The ratios of the anodic and cathodic peak current were increased with increasing scan rates. The Randles-Sevcik equation (3) [2021] shows that:

$$
\mathrm{I}_{\mathrm{p}}=\left(2.69 \times 10^{5}\right) \mathrm{n}^{3 / 2} \mathrm{AC} \mathrm{D}^{1 / 2} \mathrm{v}^{1 / 2}
$$

where $\mathrm{I}$ is the current; $\mathrm{n}$ is the number of moles of electrons transferred in the reaction; $\mathrm{A}$ is the area of the electrode; $\mathrm{D}$ is the diffusion coefficient; and $\mathrm{v}$ is the scan rate of the applied potential.

The diffusion coefficient values of both anodic and cathodic current peaks of nicotine in a blood medium on GCE were determined from Randles-Sevcik equations, as shown in Table 1, which indicate that the charge transfer reaction in the nicotine - blood complex occurred with a high diffusion controlled system [22].

Table 1. Redox current potential, peak potential separation, peak current ratio and diffusion coefficient $\left(\mathrm{D}_{\mathrm{f}}\right)$ of the nicotine in a blood medium, at different scan rates on GCE.

\begin{tabular}{|c|c||c|c||c|c||c||c||c||}
\hline $\begin{array}{c}\text { Scan } \\
\text { rate }\end{array}$ & $\begin{array}{c}\mathbf{I}_{\mathbf{p c}} \\
\boldsymbol{\mu A}\end{array}$ & $\begin{array}{c}\mathbf{E}_{\mathbf{p c}} \\
\mathbf{m V}\end{array}$ & $\begin{array}{c}\mathbf{I}_{\mathbf{p a}} \\
\boldsymbol{\mu A}\end{array}$ & $\begin{array}{c}\mathbf{E}_{\mathbf{p a}} \\
\mathbf{m V}\end{array}$ & $\begin{array}{c}\mathbf{E}_{\mathbf{p a}}-\mathbf{E}_{\mathbf{p c}} \\
\mathbf{m V}\end{array}$ & $\mathbf{I}_{\mathbf{p a}} / \mathbf{I}_{\mathbf{p c}}$ & $\begin{array}{c}\mathbf{D}_{\mathbf{f}}, \mathbf{p}_{\mathbf{c}}, \\
\mathbf{c m}_{\mathbf{2}} \mathbf{~ s}^{-2}\end{array}$ & $\begin{array}{c}\mathbf{D}_{\mathbf{f}}, \mathbf{p}_{\mathbf{a}}, \\
\mathbf{c m ~ s}^{-2}\end{array}$ \\
\hline 0.1 & 8.9 & 551 & 20.5 & 663 & 112 & 2.3 & $4.4 \times 10^{11}$ & $23.3 \times 10^{11}$ \\
\hline \hline 0.01 & 3.43 & 456 & 5.17 & 576 & 120 & 1.5 & $6.5 \times 10^{11}$ & $14.8 \times 10^{11}$ \\
\hline \hline 0.08 & 6.33 & 557 & 15.9 & 636 & 79 & 2.5 & $2.7 \times 10^{11}$ & $17.5 \times 10^{11}$ \\
\hline 0.09 & 6.7 & 578 & 23.8 & 663 & 85 & 3.5 & $2.7 \times 10^{11}$ & $34.9 \times 10^{11}$ \\
\hline
\end{tabular}

Table 2. Reliability of GCE as working electrode at SR $\left(100 \mathrm{mV} \mathrm{s}^{-1}\right)$ for the anodic current peak of nicotine in a blood medium at ten times.

\begin{tabular}{|c|c|c|c|}
\hline Numbers & $\begin{array}{c}\mathbf{I}_{\mathbf{p a}} \\
(\boldsymbol{\mu} \mathbf{A})\end{array}$ & Mean & RSD \\
\hline 1 & 18.0 & \multirow{10}{*}{18.45} & \multirow{10}{*}{ $\pm 1.60 \%$} \\
\hline 2 & 18.1 & & \\
\hline 3 & 18.2 & & \\
\hline 4 & 18.3 & & \\
\hline 5 & 18.4 & & \\
\hline 6 & 18.5 & & \\
\hline 7 & 18.6 & & \\
\hline 8 & 18.7 & & \\
\hline 9 & 18.8 & & \\
\hline 10 & 18.9 & & \\
\hline
\end{tabular}

\section{Reliability and stability}

The potential cycling of the oxidation-reduction current which was carried out during cyclic voltammetry for GCE in nicotine with a blood medium at SR is 100 $\mathrm{mVs}^{-1}$. 
Table 2 illustrates the reliability of the current of the anodic current peak $\left(\mathrm{I}_{\mathrm{pa}}\right)$ and the relative standard deviation (RSD), which is $\pm 1.6 \%$.

Fig. 8 shows the $\mathrm{CV}$ of redox current peaks of nicotine with a blood medium at ten times, which revealed a good stability of the CV of the GCE by overlapping of the voltammogram at ten times.

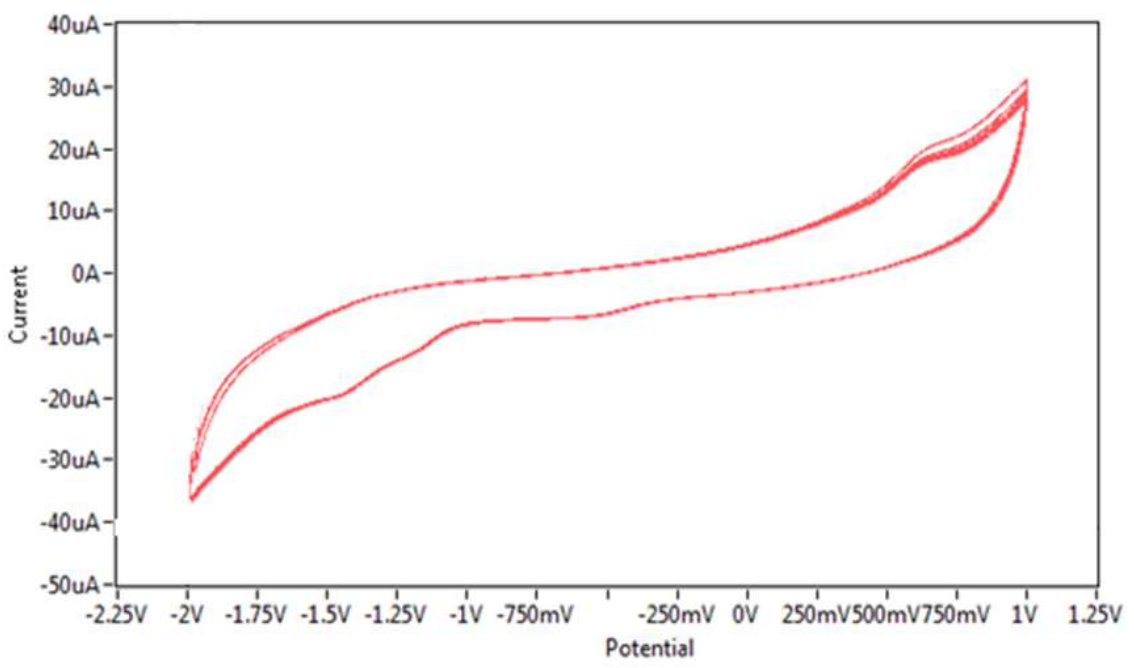

Figure 8. Cyclic voltammogram of nicotine in a blood medium at ten times, using GCE and $\mathrm{Ag} / \mathrm{AgCl}$ as reference electrode, with a scan rate of $100 \mathrm{mVs}^{-1}$.

\section{Interference of nicotine with the blood compound}

The effect of nicotine compound in cigarette tobacco on blood components was studied by electrochemical method using cyclic voltammetric technique. It was noted the effect of oxidative stress in the blood, especially when the nicotine compound is associated with blood hemoglobin as a complex and configured with iron, causing the appearance of many oxidation current peaks in the cyclic voltammogram. Smokers must be advised to refrain from smoking to avoid the effect of oxidative stress and cancer disease in blood.

\section{Conclusion}

In this study, the results demonstrate the suitability of GCE using cyclic voltammetric technique to investigate the effect of nicotine in blood media; a low nicotine oxidation current peak was obtained at alkaline $\mathrm{pH}$ values, and many oxidation current peaks at neutral and acidic $\mathrm{pH}$ values. The study has proved that different temperatures had an effect on oxidation - reduction current peaks. Also, increasing scan rates cause the enhancement of the oxidation current peaks of nicotine. The redox process of nicotine peaks in a blood medium has a reversible reaction with a high diffusion coefficient value for both anodic and cathodic electrodes, which indicated the high resolution analysis in the results of this study. 


\section{Acknowledgment}

Authors would like to thank Dr. Omer K. Roman from the Plant Protection Center, Baghdad, Iraq.

\section{References}

1. Radhi MM, Albakry AAA, Jassim AM, et al. Electrochemical Study of $\mathrm{Pb}$ (II) in Presence of Each Ascorbic Acid, Glucose, Urea and Uric Acid Using Blood Medium as an Electrolyte. Nano Biomed Eng. 2016;8:9.

2. Radhi MM, Abdullah HN, Al-Asadi SA, et al. Electrochemical oxidation effect of ascorbic acid on mercury ions in blood sample using cyclic voltammetry. Int J Ind Chem. 2015;6:311.

3. Radhi MM, Khalaf MS, Ali ZO, et al. Voltammetric Analysis of Zn (II) in Presence of Each Ascorbic Acid (AA) and Folic Acid (FA) in Human Blood Samples. American Association for Science and Technology, AASCIT Communications. 2016;3:11.

4. Radhi MM, Tan WT, Ab Rahman MZB, et al. Voltammetric Detection of Mn(II) in Blood Sample at C60 and MWCNT Modified Glassy Carbon Electrodes. Am J Appl Sci. 2010;7:439.

5. Radhi MM, Dawood DS, Al-Damlooji NK, et al. Development of Electrochemical Sensors for the Detection of Mercury by CNT/Li+, C60/Li+ and Activated Carbon Modified Glassy Carbon Electrode in Blood Medium. Sensors Transd J. 2012;146:191.

6. Radhi MM, Al-Damlooji NK, Abed BK, et al. Electrochemical Sensors for Detecting Mn (II) in Blood Medium. Sensors Transd J. 2013;149:89.

7. Tee TW, Radhi MM, Ab Rahman MZ, et al. Application studies to voltammetric detection of trace $\mathrm{Hg}$ (II) by different modified solid glassy carbon electrode. Aust J Basic Appl Sci. 2013;5:2475.

8. Doolittle DJ, Winegar R, Lee JK, et al. Mutat Res. 1995;344:95.

9. Highton L, Kadara RO, Jenkinson N, et al. Electroanalysis. 2009;21:2387.

10. Wang SN, Xu P, Tang HZ, et al. Biotechnol Lett. 2004;26:1493.

11. Kataoka H, Inoue R, Yagi K, et al. J Pharm Biomed Anal. 2009;49:108.

12. Russell MA, Jarvis M, Iyer R, et al. Relation of nicotine yield of cigarettes to blood nicotine concentrations in smokers. Br Med J. 1980;280:972.

13. Benowitz NL, Hukkanen J, Jacob P. Nicotine Chemistry, Metabolism, Kinetics and Biomarkers. Handb Exp Pharmacol. 2009;192:29.

14. Jolma CD, Samson RA, Klewer SE, et al. Acute cardiac effects of nicotine in healthy young adults. Echocardiography. 2002;19:443.

15. Neal B, Steven GG. Cardiovascular Toxicity of Nicotine: Implications for Nicotine Replacement Therapy. J Am Coll Cardiol. 1997;29:1422.

16. Levent A, Yavuz Y, Zuhre S. Voltammetric behavior of nicotine at pencil graphite electrode and its enhancement determination in the presence of anionic surfactant. Electrochimica Acta. 2009;55:190.

17. Hailemariam K, Alemnew G, Shimelis A. Voltammetric determination of nicotine in cigarette tobacco at electrochemically activated glassy carbon electrode. Bull Chem Soc Ethiop. 2013;27:321 
18. Tan WT, Lim E, Bond A. Preparation and characterization of tin oxide, $\mathrm{SnO}_{2}$ nanoparticles decorated grapheme. J Sol State Electrochem. 2003;7:134-140.

19. Jacob S, Hong Q, Coles B, et al. Variable-Temperature Microelectrode Voltammetry: Application to Diffusion Coefficients and Electrode Reaction Mechanisms. J Phys Chem. 1999;103:2963.

20. Zanello P. Inorganic Electrochemistry: Theory, Practice and Application.

London: The Royal Society of Chemistry; 2003.

21. Crouch SR, Skoog DA. Principles of instrumental analysis. Florence: Cengage Learning; 2006.

22. Mamun MA, Omar APK, Bakshi MQE. (2010) Synthesis and spectroscopic, magnetic and cyclic voltammetric characterization of some metal complexes of methionine: [(C 5H 10NO 2S) 2M II]; M II = Mn(II), Co(II), Ni(II), $\mathrm{Cu}(\mathrm{II}), \mathrm{Zn}(\mathrm{II}), \mathrm{Cd}(\mathrm{II})$ and $\mathrm{Hg}(\mathrm{II})$. J Saudi Chem Soc. 2010;14:23. 